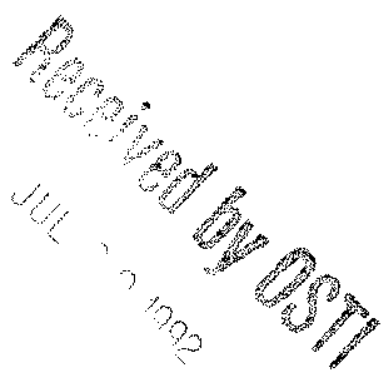

\title{
Evaluation of Source-Term Data for
} Plutonium Aerosolization

\section{LOS AIDIROS}

Los Alamos National Laboratory is operated by the Unizersify of California for the United States Department of Energy under contract W-7405-ENG-36. 
An Affirmative Action/Equal Opportunity Employer

This report was prepared as an account of work sponsored by an agency of the United States Government. Neither The Regents of the University of California, the United States Government nor any agency thereof, nor any of their employees, makes any uarranty, express or implied, or assumes any legal liability or responsibility for the accuracy, completeness, or usefulness of any information, apparatus, product, or process disclosed, or represents that its use would not infringe privately owned rights. Reference herein to any specific commercial product, process, or service by trade name, trademark, manufacturer, or otherwise, does not necessarily constitute or imply its endorsement, recommendation, or fworing by The Regents of the University of California, the United States Government, or any agency thereof. The views and opinions of authors expressed herein do not necessarily state or reflect those of The Regents of the University of Colifornia, the United States Government, or any agency thereof. 
Evaluation of Source-Term Data for

\section{Plutonium Aerosolization}

John M. Haschke 


\title{
EVALUATION OF BOURCE-TERM DATA FOR PLUTONIUM AEROSOLIZATION
}

by

John M. Haschke

\begin{abstract}
Relevant data are reviewed and evaluated in an effort to define the time dependence and maximum value of the source term for plutonium aerosolization during a fuel fire. The rate of plutonium oxidation at high temperatures is a major determinant of the time dependence. Analysis of temperature-time data for oxidation of plutonium shows that the rate is constant (0.2 $\mathrm{g} \mathrm{PuO}_{2} / \mathrm{cm}^{2}$ of metal surface per min) and independent of temperature above $500^{\circ} \mathrm{C}$. Total mass and particle distributions are derived for oxide products formed by reactions of plutonium metal and hydride. The mass distributions for products of all metal-gas reactions are remarkably similar with approximately 0.07 mass? of the oxide particles having geometric diameters $\leq 10 \mu \mathrm{m}$. In comparison, 25 mass? of the oxide formed by the $\mathrm{PuH}_{2}+\mathrm{O}_{2}$ reaction is in this range. Experimental values of mass fractions released during oxidation are evaluated and factors that alter the release fraction are discussed.
\end{abstract}

\section{INTROUUCTION}

A broad spectrum of concerns are associated with the transportation of special nuclear materials. An accident scenario of interest is the possible dispersion of plutoniumcontaining particles into the environment if a shipping container for plutonium metal or a reactive plutonium compound is involved in a fuel fire. Reliable estimates of the hazards posed by such a plutonium release are contingent on the availability of technical data to define the source term for 
aerosolization of plutonium oxide particles. Although several studies of plutonium aerosolization by burning metal are reported, ${ }^{1-5}$ essential data are undefined. Information pertinent to plutonium release during self-sustained oxidation of plutonium has recently been reviewed and evaluated, 6 but the concerns addressed in that assessment differ significantly from those created by an external fire.

The aerosolization source term for the incident outline above varies during the course of the fire. The formation of aerosolizable particles from the non-aerosolizable metal is a complex process characterized by three distinct stages. The release probability and the source term are zero for a period of time during which the container temperature remains below the $640^{\circ} \mathrm{C}$ melting point of plutonium and the integrity of the container is preserved. The source term becomes non-zero when the container is breached by highly corrosive molten plutonium. Whereas most refractory metals such as $\mathrm{Ti}, \mathrm{V}, \mathrm{Ta}$ and $W$ have limited solubilities in liquid plutonium ${ }^{7}$ and are breached rather slowly, other metals such as steel readily form low-melting intermetallic phases ${ }^{7}$ and are more rapidly breached. During this second stage, the source term increases with time as liquid metal progressively escapes from the container and reacts to form particles of plutonium oxide. The rates of these processes determine the length of time required to convert the metal to oxide, and the rate at which the source term increases from zero to a constant maximum value marked by complete oxidation. During the third stage the source term is invariant and defined by the total quantity of plutonium oxide and the aerosolizable fraction of that product. The maximum theoretical amount of oxide may not be dispersed because of kinetic limitations; the length of time to approach that point is very incident specific.

This report addresses important factors for defining the time dependence of the source-term and its maximum value for the scenario of interest. These factors are the oxidation kinetics of plutonium metal and plutonium hydride at 
temperatures up to $1000^{\circ} \mathrm{C}$, the particle distribution of products formed by those reactions and the kinetics of processes limiting entrainment of particles. Since some of the required information is divergent or unavailable, the conclusions of this report are based on a broad spectrum of literature describing fundamental and engineering studies and in certain cases rely on the use of interpolation, extrapolation and modeling.

\section{PUNDAYENTAL PROPERTIES}

Pertinent Physical and Chemical Properties Plutonium is a reactive metal exhibiting complex properties and forming stable compounds with most other elements. The unalloyed metal has six allotropic forms between room temperature and its melting point at $640^{\circ} \mathrm{C} .{ }^{8}$ Differences in hardness and other properties are observed for each phase. Unalloyed plutonium, often described as "alpha phase," is a hard metal existing at room temperature. since this form of $\mathrm{Pu}$ is only stable up to $122^{\circ} \mathrm{C}$, the alpha phase is not actually present at the temperatures of interest. The delta phase is a malleable metal normally existing in the 315 to $457^{\circ} \mathrm{C}$ range, but this form occurs over a wide temperature range when plutonium is alloyed with gallium. The delta-phase alloy containing approximately 1 mass $\mathrm{Ga}$ is stable when cooled to room temperature.

Plutonium forms two oxides, $\mathrm{Pu}_{2} \mathrm{O}_{3}$ and $\mathrm{PuO}_{2}$. These friable crystalline phases are thermodynamically stable; their respective free energies of formation at $25^{\circ} \mathrm{C}$ are -378 and $-238.5 \mathrm{kcal} / \mathrm{mol} .9 \mathrm{Pu}_{2} \mathrm{O}_{3}$, the lower-composition equilibrium product formed during oxidation of plutonium metal, is readily converted to $\mathrm{PuO}_{2}$ in air. This conversion is so facile that only $\mathrm{PuO}_{2}$ is observed on the surface of the metal under 500 torr $\mathrm{O}_{2}$ at temperatures up to $500^{\circ} \mathrm{C} .10$

plutonium forms a complex series of hydrides in the com-

position range bounded by $\mathrm{PuH}_{2}$ and $\mathrm{PuH}_{3} \cdot{ }^{11}$ The cubic di- 
hydride structure readily accommodates additional hydrogen, and a continuous solid solution forms between $\mathrm{PuH}_{2}$ and $\mathrm{PuH}_{3}$ as the temperature and hydrogen pressure are varied. The free energies of formation of $\mathrm{PuH}_{2}$ and $\mathrm{PuH}_{3}$ at $25^{\circ} \mathrm{C}$ are -31.2 and $-40.4 \mathrm{kcal} / \mathrm{mol}$, respectively. The hydrides are pyrophoric crystalline materials that react violently to form $\mathrm{PuO}_{2}$ upon exposure to air.

The sizes of product particles formed by the $\mathrm{Pu}+\mathrm{O}_{2}$ and $\mathrm{Pu}+\mathrm{H}_{2}$ reactions are strongly dependent on the reaction temperature. Whereas all oxide particles formed at low temperature are $5 \mu \mathrm{m}$ or less in size, ${ }^{12}$ particles with diameters exceeding $3 \mathrm{~mm}$ are formed at temperatures above $500^{\circ} \mathrm{C} .^{1}$ In a parallel way, the hydride obtained near room temperature is a fine powder and that formed at temperatures above $300^{\circ} \mathrm{C}$ contains centimeter-sized particles. ${ }^{13}$ Possible origins of this temperature dependence are discussed in the next section.

\section{oxidation Mechanisms}

An understanding of the physical processes associated with oxidation of plutonium metal and hydride provides a basis for evaluating data relevant to source-term evaluation. The oxidation behavior of metal by air and oxygen is well defined and pertinent references are cited in recent reports. 10,14 Plutonium oxidation is a "paralinear" process involving three stages shown by the curve in Figure 1. If a clean metallic surface is exposed to oxygen, the extent of the ensuing reaction follows a functionality characteristic of a diffusion-controlled process. As the thickness of the adherent oxide layer increases on the metal surface, the rate of oxygen diffusion through that layer decreases according to a parabolic curve like that observed for stage $I$ in Figure 1 .

The formation of oxide particles begins during stage II. The second stage is characterized by a linear reaction extenttime curve with a slope that defines the constant oxidation rate. At the onset of stage II, the thickness of the adherent 
product layer attains a critical value determined by the buildup of stress induced by forming low-density oxide (molar volume $=23.67 \mathrm{~cm}^{3} / \mathrm{mol}$ ) on the high-density metal (molar volume $=12.20 \mathrm{~cm}^{3} / \mathrm{mol}$ ). This stress is relieved by cracking and spalling of the oxide layer. Localized enhancement of the reaction rate occurs at spallation sites. As the oxide thickness increases at these reactive sites, the resulting decrease in rate is offset by spallation and rate enhancement at other sites. This process establishes a constant average layer thickness and a constant bulk reaction rate. stage III is a similar linear process entered after a transition period, but the origin of this change is unknown.

Variations observed in the sizes of product particles from $\mathrm{Pu}+\mathrm{O}_{2}$ and other Pu+gas reactions with temperature are consistent with the spallation mechanism described above. The observed increase in particle size with increasing reaction temperature is interpreted as a combination of two factors. The first of these is variation of metal hardness and malleability with temperature. Hardness data for the allotropes of plutonium show a progressive decrease with each phase transition and a five-fold difference in the hardness value for alpha and delta phases. 15 The increasing malleability of plutonium with temperature reduces the stress generated at the product-metal interface and promotes formation of a thicker product layer before spallation occurs. Data for several actinide metal + hydrogen reactions indicate that formation of centimeter-sized hydride particles occurs if the reaction temperature equals or exceeds half the melting temperature of the metal in degrees centigrade. 13

A second factor that may alter product particle size is kinetic in nature. Spallation of particles via a stress cracking process involves nucleation of cracks at the surface and propagation of those cracks through the stressed material with ultimate coalescence and formation of free particles. Nucleation and propagation are both time-dependent, and the time period available for their occurrence is important in 
determining particle size. Although the temperature dependence of spallation is unknown, the activation energies are probably small compared to the $\mathrm{E}_{\mathrm{a}}$ of $33 \mathrm{kcal} / \mathrm{mol}$ for stage II oxidation. 10 consequently, the growth rate of the oxide layer is large compared to the spallation rate at high temperatures and formation of large particles is favored. At room temperature the oxide growth rate is extremely slow and the longer time available for spallation favors extensive crack formation and small particle sizes. Since the activation energy for $\mathrm{Pu}+\mathrm{H}_{2}$ is low $\left(E_{a}=2.0 \mathrm{kcal} / \mathrm{mol}\right)^{13}$ and the hydriding rate at room temperature is $10^{6}$ times faster than the rate for $\mathrm{Pu}+\mathrm{O}_{2}, 16$ hydride products should contain larger particles than the oxide formed at the same temperature. Whereas the largest particle diameter observed for low-temperature hydride is near $100 \mathrm{~mm}, 17$ that for $10 \mathrm{w}-$ temperature oxide is approximately $5 \mathrm{\mu m} .12$

The oxidation of plutonium hydride is a secondary reaction for which little change in particle size is anticipated. The molar volume of $\mathrm{PuO}_{2}$ is virtually identical to that for $\mathrm{PuH}_{2}\left(23.17 \mathrm{~cm}^{3} / \mathrm{mol}\right)$ and minimal stress should exist at the oxide-hydride interface. This rationale leads to the conclusion that the particle size distributions for the hydride reactant and oxide product should coincide. Experimental observations do not support this conclusion. The count mean diameter $(1.5 \mu \mathrm{m})$ measured for the oxide product of the $\mathrm{PuH}_{2}+\mathrm{O}_{2}$ reaction 18 is noticeably shifted relative the mean value $(5.0 \mathrm{~m})$ for the hydride ${ }^{17}$ and the BET (Brunauer, Emmett, Teller) surface area of the sample increases by a factor of 3 to 5 during oxidation. 19

The spallation mechanism occurring during hydride oxidation apparently involves a physical process other than interface stress produced by reactant-product mismatch. The observed decrease in particle size is consistent with a conceptual fracture mechanism based on fundamental properties of oxide and hydride. During oxidation, the thermodynamically stable chemical arrangement does not involve release of 
gaseous hydrogen, but its adsorption to form a higherstoichiometry hydride within the $\mathrm{PuH}_{2}-\mathrm{PuH}_{3}$ solid-solution region of the phase diagram. ${ }^{11}$ As the $\mathrm{PuO}_{2}$ layer forms on the surface of a particle, the product hydrogen dissolves in the residual hydride center of the particle. This process continues until the stoichiometry of the hydride core approaches the $\mathrm{PuH}_{3}$ limit. Additional hydrogen cannot be absorbed or readily escape through the thick oxide layer. The resulting increase in internal pressure leads to particle fragmentation.

oxidation Kinetics

The oxidation of plutonium proceeds through several stages, but all of them do not have equal impact on the source term. As shown in Figure 1, completion of the parabolic process and onset of spallation occurs after $3 \mathrm{~h}$ at $300^{\circ} \mathrm{C}$ and 1 torr oxygen pressure. The time span of stage I decreases with increasing temperature and oxygen pressure and is not a major factor in determining the onset of particle spallation at temperatures above $640^{\circ} \mathrm{C}$ and at the 160 torr $o_{2}$ partial pressure of the atmosphere. Consequently, only stages II and III need be considered for establishing the time dependence of the source term.

The anticipated kinetic behavior of the $\mathrm{Pu}^{\mathrm{O}} \mathrm{O}_{2}$ reaction at temperatures of interest is shown by Arrhenius curves in Figure 2. Solid segments of the curves show the oxidation rate, $K$, in $\mathrm{mg} \mathrm{O}_{2} / \mathrm{cm}^{2} \mathrm{~min}$ measured for stages II and III at 500 torr $\mathrm{O}_{2}$ pressure and temperatures up to $450^{\circ} \mathrm{C} .10$ Extrapolations of the temperature trends established by the data are shown by the dashed segments. The changes in slope correspond to transitions from low-temperature processes having activation energies of $19 \mathrm{kcal} / \mathrm{mol}$ to high-temperature processes having higher $\mathrm{E}_{\mathrm{a}}$ values of 33 and $46 \mathrm{kcal} / \mathrm{mol}$ for stages II and III, respectively. As shown by Figure 1, the transition from stage II to stage III occurs after an extended time period and the later stage may not be entered during the 
time frame of a fire. $K$ is also dependent on the $\mathrm{O}_{2}$ pressure, $p$, and varies as $p^{n}$. Below $400^{\circ} \mathrm{C}, K$ is rather insensitive to $P$ with $0 \leq n \leq 1 / 3$. Above $400^{\circ} \mathrm{C}, n=1 / 2$ for stage $I I$ and $n=$ 1 for stage III.

The extrapolated rate curves in Figure 2 provide a basis for predicting oxidation rates for $\mathrm{Pu} \mathrm{O}_{2}$ in air at elevated temperatures. Even for $n=1$, the pressure correction from 500 to 160 torr $\mathrm{O}_{2}$ reduces $\mathrm{K}$ by approximately a factor of two and is considered negligible. For stage II, a $40 \mathrm{~s}$ time period is calculated for completely oxidizing a $1 \mathrm{~kg} \mathrm{Pu}$ sphere in air at $1000^{\circ} \mathrm{C}$, and half of a $200 \mathrm{~g} \mathrm{Pu}$ cylinder should react in about $30 \mathrm{~s}$ at $850^{\circ} \mathrm{C}$. This prediction stands in sharp conflict with an experimental observation by stewart showing that $115 \mathrm{~g}$ of a $200 \mathrm{~g}$ cylindrical sample remained unreacted after $23 \mathrm{~min}$ in a fuel fire at $860^{\circ} \mathrm{C} .^{1}$ Possible origins of this discrepancy include: (a) error in the experimental observation (b) depletion of the oxygen concentration in the fuel fire atmosphere near the sample and (c) a change in oxidation mechanism that invalidates the Arrhenius extrapolation.

The validity of the experimental observation is seen by comparing oxidation rates derived from data reported by stewart $^{1}$ with values obtained from similar data reported by Mishima. ${ }^{3}$ Relevant data extracted from time-temperature curves are presented in Table I with average oxidation rates calculated for each test. The results obtained from stewart's data are shown by solid symbols in Figure 2 and those from Mishima's data are shown by open symbols. Error limits in the rate are based on estimated uncertainties in reaction times and sample surface areas. Three significant results are evident: (a) the oxidation rates are in agreement, but slower than predicted by Arrhenius extrapolation, (b) the rates are independent of temperature in the range above $500^{\circ} \mathrm{C}$ and (c) the rates for unalloyed metal and gallium-containing alloy are indistinguishable. Although oxidation rates measured for various Ga-containing alloys in air at room temperature are a 
factor of 10 to 100 less than that for unalloyed plutonium, 20 the oxidation rates of these metals appear to converge at a temperature near $500^{\circ} \mathrm{C} .21$ The average oxidation rate for plutonium at temperatures above $500^{\circ} \mathrm{C}$ is $0.16 \pm 0.08 \mathrm{~g}$ $\mathrm{PuO}_{2} / \mathrm{cm}^{2} \mathrm{~min}$.

The rate results provide insight into the potential effects of oxygen depletion during a fuel fire. Use of the square-root pressure dependence for the stage II rate shows that the $\mathrm{O}_{2}$ pressure at the sample must be reduced to about 0.5 torr in order to produce the apparent reduction in rate at $860^{\circ} \mathrm{C}$. Not only does this pressure seem inordinately low and improbable, but the possibility of kinetic control by oxygen depletion is virtually precluded by the other set of kinetic results. The oxidation rates for reaction in a fuel fire ${ }^{1}$ are identical to those for self-sustained burning in flowing air that provided a twenty-five-fold excess of $\mathrm{O}_{2} \cdot 3$ The existence of reducing conditions in a fuel fire merits further evaluation. Volatilization and cracking of hydrocarbons produce a non-oxidizing atmosphere. However, a significant fraction of the fuel must also burn in order to maintain a $1000^{\circ} \mathrm{C}$ flame temperature. High concentrations of $\mathrm{H}_{2} \mathrm{O}, \mathrm{CO}_{2}$ and $\mathrm{CO}$ must be present in the fire. Reactions of these species with plutonium are thermodynamically favored and are expected to occur at the temperature of the flame. For example, the reported 22 oxidation rate of delta-stabilized plutonium by water vapor at 15 torr pressure and $500^{\circ} \mathrm{C}$ equals that for alloy oxidation by $\mathrm{O}_{2}$ at 500 torr and $500^{\circ} \mathrm{C} .10$

Although a definitive explanation is not possible for the rate behavior of $\mathrm{Pu}+\mathrm{O}_{2}$ above $500^{\circ} \mathrm{C}$, a change in reaction mechanism provides the most reasonable interpretation. Three possibilities merit consideration. The first involves formation of a progressively thicker oxide layer on the metal with increasing temperature. This explanation is unlikely because the thickness increase must precisely compensate for the temperature-driven increase in transport rate across the layer. A particle size increase with temperature is not 
evident above $500^{\circ} \mathrm{C}$. An alternate possibility is the selflimiting nature of autothermic chemical reactions. 23 A limit on the rate of a self-sustaining reaction arises because thermal acceleration ceases when the point is reached where the rate of heat loss balances the rate of heat production. since the sample temperature cannot increase beyond this point, a limiting condition and a constant rate are achieved. Further evaluation of this concept is needed to determine if autothermic control is operative. The most likely explanation for the constant rate is a gas phase transport limitation occurring for gas mixtures. Removal of oxygen from the gas at the gas-solid interface produces a layer of nitrogen and other unreactive gases at the surface. The oxidation rate is controlled by the transport of oxygen or oxygenated species across that layer.

A constant oxidation rate for plutonium at temperatures above $500^{\circ} \mathrm{C}$ is unexpected and inconsistent with conclusions described in a recent review. ${ }^{6}$ According to earlier interpretations of experimental data, the rate of $\mathrm{Pu} \mathrm{O}_{2}$ at high temperatures is altered by metal type, sample mass and temperature, but the data in Table $I$ do not support these conclusions. The recommended burn rate of $180 \mathrm{~g} / \mathrm{h}$ for plutonium does not recognize the well-established dependence of rate on the surface area of metal, 10,20 and cannot be reconciled with the observed oxidation of a $1.8 \mathrm{~kg} \mathrm{Pu}$ sample in 55 min. $^{3}$ The value cannot be compared with the $0.2 \mathrm{~g}$ $\mathrm{PuO}_{2} / \mathrm{cm}^{2} \mathrm{~min}$ rate derived in this work or applied to a specific situation. Although the mathematics of source term calculation during the time-dependent period is simplified by the existence of a constant oxidation rate, definition of the oxide quantity present at a given point in time is complicated by lack of information about metal release rates and geometries of molten metal deposits formed during failure of containment vessels.

The oxidation of high-surface-area plutonium hydride is a two-stage process. 19 The initial stage is extremely rapid 
with a negative activation energy $\left(E_{\mathrm{a}}=-2.1 \mathrm{kcal} / \mathrm{mol}\right)$ suggesting that the oxidation rate is determined by the adsorption of $\mathrm{O}_{2}$ on the surface. During this stage a diffusion barrier of oxide advances toward the centers of the hydride particles and leads to a comparatively slow second stage of reaction. This is a constant-rate process over time and has $\mathrm{E}_{\mathrm{a}}=10.0 \mathrm{kcal} / \mathrm{mol}$. Incomplete oxidation is observed at low temperatures in experiments conducted over the 50 to $360^{\circ} \mathrm{C}$ range at 10 torr $\mathrm{O}_{2}$ pressure.

The kinetics of $\mathrm{PuH}_{2}+\mathrm{O}_{2}$ are altered by several factors. Increasing the reaction temperature dramatically increases the fraction of hydride consumed during the initial processes. Whereas only $20 \%$ of the hydride reacts in the initial rapid stage at $100^{\circ} \mathrm{C}$, the hydride is totally oxidized via this process at temperatures above $400^{\circ} \mathrm{C}$. At 10 torr $\mathrm{O}_{2}$ pressure the first stage is complete within minutes. ${ }^{19}$ The pyrophoric nature of the hydride powder formed at temperatures below $100^{\circ} \mathrm{C}$ is well documented and different from that of the coarse product obtained at temperatures above $300^{\circ} \mathrm{C} .{ }^{24}$ The lowtemperature hydride ignites and burns spontaneously when exposed to air; the high-temperature product only ignites in air when heated to $270^{\circ} \mathrm{C}$. Rapid and complete oxidation of either product is expected if a hydride container is breached and the shipment is exposed to a fuel fire.

\section{GIZE DI8TRIBUTIONS}

Size Distribution Data for the Product of $\mathrm{Pu}+\mathrm{O}_{2}$

Size distribution data for the product of metal oxidation are essential for source term definition. Although particle size measurements are described by various workers, distributions are only reported for selected fractions, not for an entire oxide product. Whereas the particle size distributions of products from Pu+gas reactions are strongly temperature dependent up to $500^{\circ} \mathrm{C}$, data for products obtained above $500^{\circ} \mathrm{C}$ suggest that thermal effects on size are minimal. 
Derivation of a total distribution for high-temperature oxide necessitates the combination of size distributions for large and small particles. This combination process is accomplished using distribution data for products of other Putgas reactions to correlate separate distributions of oxide particles.

Cumulative mass distributions for large particle fractions formed by high temperature oxidation are reported by stewart $^{1}$ and by Mishima. ${ }^{2}$ The log-normal distributions of geometric particle diameters measured by stewart for the fractions not entrained by the up-draft in fuel fire experiments are shown in Figure 3. Data for the residue obtained at $860^{\circ} \mathrm{C}$ (solid circles) are in good agreement with those for a $500^{\circ} \mathrm{C}$ product (open circles), but only the second distribution accounts for the entire oxide mass. As shown by solid triangles, a partial distribution ${ }^{2}$ of an unentrained oxide residue formed by combustion in flowing air at temperatures up to $560^{\circ} \mathrm{C}$ is in good agreement with those for fuel-fire tests.

The curve defined by solid symbols in Figure 4 shows the cumulative particle distribution measured by Mishima ${ }^{3}$ for an oxide fraction entrained by an air flow of $5.25 \mathrm{~m} / \mathrm{sec}$ (11.7 mph). The sample was collected during self-sustained combustion of a $1.8 \mathrm{~kg}$ metal sample at $925^{\circ} \mathrm{C}$. The data provide a uniquely detailed picture of particle dimensions in the micron and submicron size range, but their contribution to the total distribution of oxide particles is unknown.

Essential information for deriving a total distribution for the oxide is obtained by evaluating particle size data reported for products formed by reactions of plutonium with other gases. The cumulative particle distribution for plutonium hydride is derived from a distribution for powdered plutonium metal.17 The metal was initially prepared by hydriding massive plutonium at room temperature and then thermally decomposing the hydride in vacuum to regenerate the metal.13 since the BET surface areas of the hydride and metal powders are identical and invariant after repeated hydride- 
dehydride cycles, the geometric particle size distribution measured for the metal is adopted for the hydride. The cumulative particle size data obtained from the distribution presented by stakebake ${ }^{17}$ are listed in Table II with size-mass fraction data calculated for spherical particles with the stated geometric diameters. The resulting cumulative mass distribution for the hydride is shown by open triangles in Figure 3. A renormalized cumulative particle distribution for hydride sizes less than $10 \mu \mathrm{m}$ is shown by open circles in Figure 4 .

Several aspects of the size distributions in Figure 3 are important in defining a total distribution for plutonium oxide. Key features of the curves are their shapes and their regions of coincidence. The total mass distributions for oxide and hydride are defined by two linear segments implying bimodel distributions of particles in both products. Whereas the dimensions of the largest oxide particles are about $1 \mathrm{~mm}$, the largest hydride particles are about $0.1 \mathrm{~mm}$ in size. This difference in large particle sizes contrasts sharply with the remarkably close agreement observed for all distributions in the size range below $50 \mu \mathrm{m}$. These features appear to be characteristic of the distributions for products of all Pu+gas reactions, not a fortuitous coincidence. Small particles with similar sizes might be formed during spallation processes that produce dissimilar large particles. Regardless of the basis for this coincidence, it suggests that distribution data for the hydride might be used as a guide for reconstructing a total distribution for high-temperature oxide formed by $\mathrm{Pu}_{2} \mathrm{O}_{2}$. Additional insight is gained from a parallel examination of the particle distributions in Figure 4. Although the resolution of particle fractions is much less for hydride than for oxide, the agreement observed between the curves suggests that the coincidence of particle sizes beginning near $50 \mu \mathrm{m}$ is maintained into the submicron range. The count mean diameter $(1.3 \mu \mathrm{m})$ for hydride particles $\leq 10 \mu \mathrm{m}$ is in close agreement with that $(1.2 \mu \mathrm{m})$ for the entrained oxide. The small 
difference appearing at the upper end of the distribution may occur because the tubular collection apparatus used by Mishima ${ }^{3}$ for sampling the airborne fraction tends to exclude particles with large diameters. ${ }^{25}$ The observed coincidence of distributions suggests that hydride data can be substituted for oxide data in the small particle range.

Derivation of a meaningful total mass distribution for plutonium oxide requires that the distribution for large and small particles be combined without skewing the result. A reasonable approach is suggested by examining the mass distributions data for hydride in Table II and that for oxide in Figure 3. A small fraction (0.2\%) of the hydride mass appears in the $15 \mu \mathrm{m}$ cumulative fraction and 1.88 of the mass is included in the $30 \mu \mathrm{m}$ cumulative fraction. A comparable amount (1.2\%) of the mass is included in the $32 \mu \mathrm{m}$ fraction of oxide residue. The two distributions may be combined by substituting the $30 \mu \mathrm{m}$ cumulative mass fraction of hydride for the $32 \mu \mathrm{m}$ cumulative mass fraction of the oxide.

The total mass distribution derived for high-temperature $\mathrm{PuO}_{2}$ by the substitution method is presented in Table III and Figure 5. Comparison of the total distribution with the partial distribution in Figure 3 shows that all features of the oxide data are reproduced by the composite curve. Greater detail in the definition of small particle sizes is achieved by redistributing the $1.5 \mu \mathrm{m}$ fraction for the hydride in accordance with Mishima's data in Figure 4. The accompanying particle distribution in Table III is based on a spherical particle assumption.

Size Distribution Data for the Product of $\mathrm{PuH}_{2}+\mathrm{O}_{2}$ size distributions of oxide particles produced by oxidation of plutonium hydride are described in studies by Edison et al. 4,5 and by Stakebake and Robinson. 18 Using the results of an extensive investigation of several Pu+gas reactions involving air, a mixture of gases designed to simulate combustion products of organics, $\mathrm{H}_{2}$, an $\mathrm{H}_{2}+\mathrm{N}_{2}$ mixture 
and $\mathrm{H}_{2}$ followed by air exposure, Edison et al. conclude that the respirable particle fraction produced by exposing hydride to air is not significantly different from the fractions produced by other Pu+gas reactions. In earlier work, Stakebake and Robinson observed that oxidation of the hydride by air is accompanied by substantial particle size changes and by an increase in surface area. ${ }^{18}$ This behavior is consistent with the pyrophoric nature of the hydride and the results reported by Stakebake and Robinson are selected as the basis for defining the size distribution of oxide formed from hydride.

The particle size distribution measured by Stakebake and Robinson 18 for the $\mathrm{PuH}_{2}+\mathrm{O}_{2}$ product is shown by the open symbols in Figure 6 . Although $95 \%$ of the particles are included in the $8 \mu \mathrm{m}$ cumulative fraction, the distribution of larger particles is undefined. As evidenced by comparing typical mass and particle distributions in Tables II and III, a substantial fraction of the mass usually resides in the largest 58 of the particles. The particle distribution given in Table IV is obtained by assuming that the linear log-normal particle distribution applies to particle sizes in excess of 8 $\mu \mathrm{m}$. The accompanying mass distribution in Table IV is derived using a spherical particle assumption. The log-normal mass distribution defined by these data is shown by open symbols in Figure 7.

Size Distribution Modeling of Secondary Products

Extrapolation of the particle distribution for the $\mathrm{Pu}_{2}$ product beyond the 958 cumulative fraction seems insignificant, but the potential impact on the mass distribution is substantial. The largest $5 \%$ of the particles accounts for $80 \%$ of the oxide mass. The derived mass distribution is strongly dependent on extrapolated data and the second linear segment suggesting a bimodal mass distribution (cf. Figure 7) is based solely on extrapolation. A model for describing the fragmentation of reactant particles 
during a secondary reaction like $\mathrm{PuH}_{2}+\mathrm{O}_{2}$ is developed in an effort to independently predict the product size distribution.

In concept, the fracture model applies a fixed fragmentation pattern to reactant particles having a known distribution and constructs a new distribution for the product. The basic assumption for defining the fragmentation pattern is that each spherical reactant particle with diameter d fractures to form new spherical particles. As shown by a two-dimensional section through a reactant sphere in Figure 8, the fragmentation pattern is defined by a closest-packed planar array of spheres with diameters $d_{1}, d_{2}$, and $d_{3}$ having magnitudes of $0.33 \mathrm{~d}, 0.13 \mathrm{~d}$, and $0.05 \mathrm{~d}$, respectively. The reactant sphere is approximated by adding an identical layer above and another below the initial array and by filling peripheral recesses on the upper and lower surfaces with $d_{2}$ spheres. Each reactant sphere produces $21 d_{1}$ spheres, $30 d_{2}$ spheres and $18 d_{3}$ spheres. Since this composite array fills only 828 of the original sphere volume, the residual volume is distributed proportionally among the three fractions such that $91.65 \%$ of the volume or mass of the original sphere appears as $d_{1}$ spheres, 8.128 appears as $d_{2}$ spheres and 0.238 appears as $d_{3}$ spheres. Each individual mass fraction in the reactant distribution is reassigned according to these percentages. The new mass distribution is generated by categorizing and summing the product masses in appropriate fractions.

Mass and particle distributions derived for the $\mathrm{PuH}_{2}+\mathrm{O}_{2}$ product using the fracture model are presented in Table $v$. These results are based on the size distribution for $\mathrm{PuH}_{2}$ in Table II after the $1.5 \mu \mathrm{m}$ fraction was repartitioned to define a $0.5 \mu \mathrm{m}$ fraction containing a mass fraction of $3.0 \times 10^{-9}$. The fracture model was applied to hydride particles with sizes $\geq$ $15 \mu \mathrm{m}$. Masses of particles with sizes $\leq 8 \mu \mathrm{m}$ were combined with those of new fragments to generate the mass distribution in Table $\mathrm{V}$. The corresponding particle distribution is based on spherical particle assumption. 
The effectiveness of the fracture model in predicting size distributions of secondary reaction products is evidenced by evaluating the results for $\mathrm{PuH}_{2}+\mathrm{O}_{2}$. The merits of the model are demonstrated by the correspondence of measured (open circles) and predicted (solid circles) particle distributions in Figure 6. A parallel comparison of the mass distributions is shown in Figure 7. The agreement is somewhat surprising. Whereas the count mean diameter measured by stakebake and Robinson ${ }^{18}$ is $1.5 \mu \mathrm{m}$, that predicted by the model is $1.9 \mu \mathrm{m}$. A bimodal mass distribution is also predicted and the mass fraction existing in the large particle distribution corresponds well with that derived by extrapolation of the experimental particle distribution. An additional evaluation is made by calculating the increase in surface area during reaction and comparing the anticipated increase with the three-fold to five-fold change observed during oxidation. 19 As expected, the calculated areas for spherical particles are 10 to 20 times less than the experimental BET values, but fragmentation according to the model produces a 2.9 fold increase in surface area. closer agreement between the observed and predicted quantities would be achieved by fracturing all particles and by forming larger particles through failed fracture in a small percentage of cases.

\section{THE RELEABED FRACTION}

Comparison of Observations

The mass fraction of oxide lost from a particle source is described in the literature $e^{1-6}$ by a variety of terms that carry a spectrum of connotations. The terminology used by Mishima ${ }^{3}$ seems most consistent with the focus of this report. The material removed from the source by entrainment in the existing draft is described as the "released fraction".

Experimental values of the released fraction are based on measurements of the plutonium quantity entrained by gases flowing over the metal during oxidation. The experimental 
conditions of various studies are diverse and cannot be compared on a common basis. This situation may be advantageous because data from a spectrum of conditions helps to establish a range of values that might be anticipated. The comparison of empirical released fractions with particle size data is a complex issue. Since size measurements of released fractions have maximum geometric dimensions approaching 10 $\mu \mathrm{m},{ }^{3}$ this diameter provides a reasonable limit for entrainment and is adopted for evaluating data in this report.

Measurements of released fractions are described in several reports. In two early experiments by stewart, 1 plutonium samples placed on a stainless steel mesh were burned in the up-draft of a fuel fire at temperatures up to $900^{\circ} \mathrm{C}$. Additional test conditions are listed in Table $I$. The released fractions obtained from the differences between the initial masses and those collected in a tray below the sample are 0.01 and 0.03 . However, as shown in Table $I$, the corresponding fractions are 0.002 and 0.008 when based on the masses of plutonium determined by integration of deposition contours. In a later publication, 26 the author concludes that a mass fraction of 0.001 is a conservative estimate of the dispersal.

Tests by Mishima ${ }^{3}$ were conducted with ignited metal samples in the forced up-draft of a collection apparatus. Conditions of these studies are also presented in Table $I$. Results are reported as release rates with values in the $4.5 \times 10^{-3}$ to $3.2 \times 10^{-2}$ mass $/ \mathrm{h}$ range. However, Mishima's data provide a basis for evaluating the released fraction. since particle collection times for two experiments are shorter than the time periods required for complete oxidation of the metal, the quantities of oxide present during collection must be calculated as a basis for evaluating the released fraction. In all cases, zero time for oxidation and collection are assumed to coincide. The amounts of oxide formed during the collection periods are defined by the length of collection, the sample surface area and the oxidation rate 
(0.2 $\left.\mathrm{g} \mathrm{PuO}_{2} / \mathrm{cm}^{2} \mathrm{~min}\right)$. The resulting released fractions in Table I are in good agreement and suggest that significant differences do not exist between the behavior of alloyed and unalloyed plutonium.

Results of an extensive set of release experiments are described by Edison et al.4,5 who studied the metal+gas reactions of delta-stabilized plutonium and alloys of plutonium with iron and uranium at $450^{\circ} \mathrm{C}$. Gaseous reactants are those noted in the preceding discussion of particle size data for $\mathrm{PuH}_{2}+\mathrm{O}_{2}$. The mean released fraction determined for $\mathrm{Pu}, \mathrm{Pu}-\mathrm{Fe}$ alloy and $\mathrm{Pu}-\mathrm{U}$ alloy with all gaseous reactants are $0.00021,0.00055$ and 0.00038 , respectively. Evaluation of release data for all metals with $\mathrm{H}_{2}$, simulated organic combustion mixture and $\mathrm{H}_{2}+\mathrm{N}_{2}$ mixture yield average released fractions of $0.00026,0.00032$ and 0.00026 , respectively. Similar analyses of data for reaction of $\mathrm{Pu}-\mathrm{Fe}$ and $\mathrm{Pu}-\mathrm{U}$ alloys with air and for reaction of all metals with $\mathrm{H}_{2}$ followed by air exposure give released fractions of 0.00050 and 0.00076 , respectively. The global average released fraction of 0.00038 obtained from the tests by Edison et al. 5 agrees with the 0.00027 value obtained from the results of Mishima. ${ }^{3}$

The mass distribution derived for the product of $\mathrm{Pu}+\mathrm{O}_{2}$ is consistent with the measured released fractions. As shown by Figure 5, the $10 \mu \mathrm{m}$ cumulative particle size encompasses a mass fraction near 0.0007 . This fraction is a factor of two larger than the empirical values from $\mathrm{Mishima}^{3}$ and from Edison et $a 1.5$ and is considered to represent the maximum entrainable fraction for oxide formed by high-temperature oxidation of plutonium.

Fundamental properties of stress-driven spallation reactions are implied by the observed agreement of released mass fractions for all $\mathrm{Pu}$ alloy+gas reactions and the coincidence of mass and particle distributions shown in Figures 3 and 4 . The products of spallation reactions at high temperatures have bimodal mass distributions and the distributions of small particles are remarkably similar 
regardless of gaseous reactant or size distribution of the large particles. These observations suggest that formation of large particles is the fundamental spallation process and that formation of small particles is a consequence of that process. An analogy can be drawn to breaking a piece of chalk. The dust and fines formed during breakage are characteristic of the fracture process, not of the sizes of the two chalk pieces formed by the fracture. The bimodal distribution and the characteristic size distribution of small particles vanish as the sizes of the large particles decrease to the point that their dimensions equal those of small particles formed during fracture. This situation is realized for the fine plutonium oxide powder produced by air oxidation at room temperature.

Particle size and released fraction data for $\mathrm{PuH}_{2} \mathrm{OO}_{2}$ are not in agreement. Although Edison and coworkers 4,5 conclude that the respirable fraction of the product formed by reaction of hydride with air is not significantly different from those of other metal+gas reactions, the mass distribution derived from data reported by stakebake and Robinson ${ }^{18}$ in Figure 7 shows that the $10 \mathrm{\mu m}$ cumulative fraction is 0.25 . The average released fraction $(0.00076)$ derived from the results of Edison et al. ${ }^{5}$ is smaller by a factor of thirty-three.

Evaluation of test observations reported by Edison et al. 5 for $\mathrm{PuH}_{2}$ tair shows that the results are inconsistent with known properties of the hydride and suggest that the experimental procedures were flawed. The hydride formed at the $450^{\circ} \mathrm{C}$ reaction temperature is a coarse product with a low surface area and non-pyrophoric nature. ${ }^{23}$ In certain cases, the products of the $\mathrm{Pu}+\mathrm{H}_{2}$ reaction had retained the shape of the metal samples. In several instances, hydrides not exposed to air changed color from black to green during cooling under argon flow. This color change is characteristic of $\mathrm{PuO}_{2}$ formation and suggests that a layer of $\mathrm{Pu}_{2} \mathrm{O}_{3}$ formed during hydriding was further oxidized during cooling. Hydride surfaces were undoubtedly passivated by an oxide layer prior 
to air exposure. At the flow rates and times of the experiments, a 1 ppm level of contamination by $\mathrm{O}_{2}$ or other oxygenated species in the gas stream would convert $0.2 \%$ of a typical sample to oxide. Sparking and spallation were observed in one case with a Pu-Fe hydride and in another instance with a Pu-U hydride; the released fractions were 0.0046 and 0.10 , respectively. Since the observations by stakebake and Robinson ${ }^{18}$ are consistent with properties anticipated for hydrides in shipment, their data are recommended for source term definition of oxide formed by the $\mathrm{PuH}_{2}+\mathrm{O}_{2}$ reaction.

\section{The Release Process}

The maximum release fraction is in principle a precisely defined point on a size distribution, but substantial variation is observed. Experimentally determined released fractions for $\mathrm{Pu}+\mathrm{O}_{2}$ bracket the anticipated value. Results of laboratory tests are a factor of two less than predicted by the $10 \mu \mathrm{m}$ point; results of fuel fire tests far exceed that value. Since these differences remain after correction for the quantities of oxide present during collection, other possible origins for their occurrence merit examination.

The velocity of air flow over the oxide source is a factor that should contribute to the observed variability in released fraction. Entrainment differences are anticipated for the $525 \mathrm{~cm} / \mathrm{s}$ flow velocity used by Mishima ${ }^{3}$ and the 40 $\mathrm{cm} / \mathrm{s}$ flow velocity used by Edison et al, 4,5 but are not evident in the measured fractions. The effect may be masked by the influence of other factors. The magnitudes of draft velocities in fuel fires should be evaluated and their effect on the source term should be more adequately defined.

other factors altering the released fraction are less readily identified and quantified. These factors include physical blockage of the oxide source from the air flow by large oxide particles and by other objects in the vicinity. A related factor is the tenacious adherence of small oxide 
particles to larger fragments. 2 The importance of entrainment is seen in the high released fractions measured by stewart. 1 The experimental design was such that each oxide particle was unavoidably entrained in the up-draft after it spalled. Particles with dimensions approaching $30 \mu \mathrm{m}$ were apparently dispersed by the fire. The likelihood of entraining such large particles from a surface source is certainly much lower than from a source placed on a mesh several feet above the burning fuel.

The conditions simulated by stewart's tests ${ }^{1}$ do not represent a credible scenario. Molten metal is not expected to remain suspended in the up-draft for an extended period of time and significant particle spallation is not expected during that period. At the high-temperature oxidation rate for $\mathrm{Pu}+\mathrm{O}_{2}$, molten metal must remain suspended for approximately $3.5 \mathrm{~min}$ in order to form a product layer having a thickness equal to the $0.6 \mathrm{~mm}$ median mass diameter observed for high temperature oxide particles. stewart's measurements lead to a substantial over-estimation of the released fraction and their use for source-term definition must be accompanied by appropriate caution.

The effects of several factors described above are apparent in the released fractions listed in Table $I$. Although Mishima ${ }^{3}$ conducted all experiments at the same air velocity and the results are corrected for oxide formation, the released fractions are strongly dependent on the collection time. A graph of the data in Figure 9 shows a linear dependence of released fraction on the length of collection. As defined by the slope, the released fraction changes by $5 \times 10^{-6}$ per minute until the maximum value is reached. The concept of a release rate has been employed by Mishima, 3 and further evaluation of this idea seems to hold merit.

Release rates derived from experimental data are surprisingly consistent. The collection intervals used for rate calculations are corrected for the fact that, on the 
average, only half of the oxide is present during the formation period or during the collection period if it is less than the formation period. The effective intervals for the sequence of three tests based on Mishima's data ${ }^{3}$ in Table I are 75,23 , and $11 \mathrm{~min}$ and the corresponding release rates are $6.2,7.8$, and $10.9 \mu \mathrm{g} \mathrm{PuO}_{2} / \mathrm{gPuO}_{2} \mathrm{~min}$. The magnitudes of these rates decrease with increasing collection time and their order is reverse of that for released fractions suggesting that the release rate is not constant with collection time, but diminishes as the release fraction approaches its maximum. The average release rate ( $5 \mu \mathrm{g} \mathrm{PuO}_{2} / \mathrm{PuO}_{2} \mathrm{~min}$ ) defined by the slope of the curve in Figure 9 is recommended.

\section{CONCLUSIONS}

Experimental data form the basis for defining size distributions and release fractions for plutonium oxide sources in fuel fires. However, the relevance of test conditions to those of interest must be evaluated in light of chemical and physical properties of plutonium metal, plutonium oxide and intermediate plutonium compounds. The effects of temperature on reaction kinetics and particle dimensions must also be understood in order to assess the relevance of experimental data.

The source term for aerosolization of plutonium oxide is strongly time-dependent in one case of interest and independent of time in another. The source term for $\mathrm{Pu}+\mathrm{O}_{2}$ varies with time until a maximum release fraction is reached. The source term for $\mathrm{PuH}_{2}+\mathrm{O}_{2}$ is virtually independent of time; the maximum releasable fraction is reached immediately after exposure to air. If the largest diameter of a releasable particle is assumed to be $10 \mu \mathrm{m}$, the maximum releasable mass fraction for $\mathrm{Pu} \mathrm{O}_{2}$ is 0.0007 and that for $\mathrm{PuH}_{2}+\mathrm{O}_{2}$ is 0.25 . The potential for aerosolization of oxide particles from $2.8 \mathrm{~g}$ of plutonium hydride equals the aerosolization potential from $1 \mathrm{~kg}$ of plutonium metal. 
Size distribution functions are remarkably similar for products of all pu+gas reactions at high temperatures. The distributions are all bimodal. Marked differences are seen in the sizes of large particles depending on reaction temperature and reaction rate. In contrast, the size distributions of small particles are remarkably similar. The coincidence of sizes in the small particle distribution is attributed to the nature of the stress-induced spallation process for Pu+gas reactions.

Observations made during the evaluation of source-term data are relevant to other safety concerns. Kinetic data for $\mathrm{Pu}+\mathrm{O}_{2}$ are essential for assessing the hazard associated with inadvertent exposure of molten plutonium to air during fabrication processes. The oxidation rate of molten metal is much less than predicted by extrapolation of Arrhenius data for solid plutonium. The observed rate $\left(0.2 \mathrm{~g} \mathrm{PuO}_{2} / \mathrm{cm}^{2} \mathrm{~min}\right)$ is independent of temperature. The maximum temperatures attained during self-sustained burning of kilogram-sized plutonium samples are less than $1000^{\circ} \mathrm{C}^{3}$ valuable information related to containment of molten plutonium during a fire are also encountered. The oxide layer formed on the metal apparently provides a containment barrier for molten plutonium and prevents the corrosion of stainless steel at temperatures up to $900^{\circ} \mathrm{C}^{1}$ This observation suggests that oxidizing environments might enhance the containment capability of steel vessels.

This report provides a new perspective on the aerosolization process for plutonium. Chemical and kinetic factors are identified and their relevance to source-term definition is developed. Several areas requiring further study are recognized. A need is seen for conducting hightemperature containment tests in an oxidizing environment. Issues requiring further definition include the rate and geometry of metal release during containment failure, the oxidation rate of plutonium metal after release and the total size distribution for the high-temperature oxide. These 
results will provide a basis for critically evaluating conclusions reached in this report and for addressing additional issues related to definition of the source term. 


\section{REFERENCES}

1. K. Stewart, "Vixen A Trials: Experiments to study the Release of Particulate Materials During the Combustion of Plutonium, Uranium and Beryllium in a Petrol Fire," AWRE Report T15/60, Atomic Weapons Research Establishment, Aldermaston, UK, January, 1961.

2. J. Mishima, "Plutonium Release studies I. Release from the Ignited Metal," USAEC Report BNWL-205, Battelle Pacific Northwest Laboratory, Richland, WA, December 1965 .

3. J. Mishima, "Plutonium Release Studies II. Release from Ignited Bulk Metallic Pieces," USAEC Report BNWL-357, Battelle Pacific Northwest Laboratory, Richland, WA, November, 1966.

4. A. F. Edison, H. C. Yeh, and G. M. Kanapilly, J. Nucl. Mater., 152 (1988) 41 .

5. A. F. Edison, H. C. Yeh, and G. M. Kanapilly, "Plutonium Aerosolization Studies," Report SW-331L, Lovelace Inhalation Toxicology Research Institute, Albuquerque, NM, March, 1987.

6. L. A. Mahoney and J. Mishima, "Assessment of the Basis for Modeling Release from Plutonium oxidation," USDOE Report PNL-SA-18402, Pacific Northwest Laboratory, Richland, WA, August, 1990.

7. F. H. Ellinger, W. N. Miner, D. R. O'Boyle and F. W. Schonfeld, "Constitution of Plutonium Alloys," USAEC Report LA-3870, Los Alamos Scientific Laboratory, Los Alamos, NM, December, 1968.

8. F. L. Oetting, M. H. Rand, and R. J. Ackermann, "The Chemical Thermodynamics of Actinide Elements and Compounds: Part 1 The Actinide Elements," International Atomic Energy Agency, IAEA, Vienna, Austria, 1976.

9. L. R. Morss, "Thermodynamic Properties," in chemistry of the Actinide Elements, 2nd. ed., Vol. 2, Chap. 17, Chapman and Hall, New York, NY, 1986.

10. J. L. Stakebake and L. A. Lewis, J. Less-Common Met., 136 (1988) 349 .

11. H. E. Flowtow, J. M. Haschke, and S. Yamauchi, "The Chemical Thermodynamics of Actinide Elements and Compounds: Part 9 The Actinide Hydrides," International Atomic Energy Agency, IAEA, Vienna, Austria, 1984. 
12. J. L. Stakebake and M. R. Dringman, J. Nucl. Mater,, 23 (1967) 349 .

13. J. M. Haschke, "Actinide Hydrides," in Topics in $f-$ Element Chemistry; Synthesis of Lanthanide and Actinide Compounds, Chap. 1, Reidel-Kluwer Academic Publishers, Dordrecht, Netherlands, 1991.

14. J. L. Stakebake, J. Less-Common Met., 123 (1986) 185 .

15. W. N. Miner, A. S. Coffinberry, F. W. Schonfeld, J. T. Waber, R. N. R. Mulford, and R. E. Tate, Rare Metals Handbook, 2nd. ed., Chap. 18, Reinhold Publishing Corp., London, United Kingdom, 1961.

16. J. M. Haschke and S. J. Hale, "Alternative Solvents for cleaning Plutonium: Thermodynamic and Kinetic Considerations," USDOE Report LA-12255-MS, LOS Alamos National Laboratory, Los Alamos, NM, March, 1992.

17. J. L. Stakebake, J. Electrochem. Soc., 128 (1981) 2383.

18. J. L. Stakebake and H. N. Robinson, Nucl. Technol,, 33 (1977) 30 .

19. J. L. Stakebake, Nucl. Sci. Eng., 78 (1981) 386.

20. J. L. Waber, Plutonium Handbook, Vol. 1, Chap. 6, American Nuclear Society, LaGrange Park, IL, 1980.

21. J. L. Stakebake, EG\&G Rocky Flats, Golden, co, Personal Communication, 1991.

22. J. L. Stakebake and M. A. Saba, J. Less-Common Met., 158 (1990) 221 .

23. J. C. Martz, "Dynamics of Metal Etching and oxidation in Fluorcarbon/Oxygen RF Glow Discharges," Doctoral Dissertation, University of California at Berkeley, Berkeley, CA, 1991.

24. J. M. Haschke, A. E. Hodges, III, and R. L. Lucas, J. Less-Common Met., 133 (1987) 155.

25. R. E. Luna, Sandia National Laboratories, Albuquerque, NM, Personal Communication, 1991.

26. K. Stewart, "The Particulate Material Formed by the oxidation of Plutonium," in Progress in Nuclear Energy, Pergamon Press, New York, NY, 1963. 


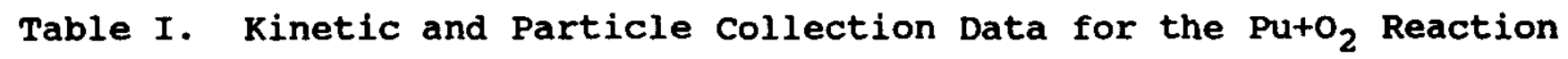

Ref.

phase

(g)

$\frac{\text { Pu sample }}{\text { starting mass area }}$

\section{Part} mass

(g) article collection

Temp. Time \& rate

Temp. Time

(min)

(1)

1
1
3
3
3

$\begin{array}{rr}203 & 41 \\ 202 & 41 \\ 568 & 68 \\ 1770 & 188 \\ 997 & 140\end{array}$

$\begin{array}{llll}860 \pm 40 & 23 \pm 7 & 43 & 12 \pm 5 \\ 500 \pm 40 & 60 \pm 20 & 100 & 11 \pm 7 \\ 900 \pm 50 & 30 \pm 5 & 100 & 37 \pm 12 \\ 925 \pm 50 & 55 \pm 5 & 100 & 27 \pm 10 \\ 775 \pm 50 & 75 \pm 5 & 100 & 13 \pm 9\end{array}$

a. Rate in $\mathrm{mgO}_{2} / \mathrm{cm}^{2} \mathrm{~min}$.

b. Particle mass reported for integrated deposition contours.

c. Mass converted to grams of $\mathrm{PuO}_{2}$ collected.

d. Released fractions based on $80 z$ completion of oxidation during 45 min collection time and $30 \%$ completion of oxidation during $22 \mathrm{~min}$ collection time. 
Table II. Size Distribution for Pu Powder Prepared by Hydriding Massive Pu and Thermally Decomposing the Hydride Product in Dynamic Vacuum. Data obtained from the particle distribution reported by stakebake. 17

Particle

Diameter ${ }^{a}$ $(\mu \mathrm{m})$
Cumulative

Particle Fraction

\author{
Cumulative \\ Mass Fraction ${ }^{b}$
}

$\begin{array}{lll}1.5 & 0.32 & 4.9 \times 10^{-7} \\ 3.0 & 0.48 & 4.3 \times 10^{-5} \\ 5.0 & 0.50 & 1.1 \times 10^{-4} \\ 8.0 & 0.60 & 5.2 \times 10^{-4} \\ 15 & 0.68 & 2.3 \times 10^{-3} \\ 30 & 0.78 & 0.018 \\ 50 & 0.83 & 0.081 \\ 70 & 0.89 & 0.22 \\ 85 & 0.95 & 0.53 \\ 95 & 0.98 & 0.80 \\ 100 & >0.99 & 0.99\end{array}$

a. Particle diameters are geometric, not aerodynamic.

b. Mass distribution calculated for spherical particles of stated diameters using $10.45 \mathrm{~g} / \mathrm{cm}^{3}$ for the $\mathrm{PuH}_{2}$ density. 
Table III. Size Distribution for $\mathrm{PuO}_{2}$ Prepared by High Temperature oxidation of $3 y$ in Air. Combined data
from stewart, 1 stakebake, 17 and Mishima.

\begin{tabular}{|c|c|c|c|c|}
\hline \multirow{2}{*}{$\begin{array}{l}\text { Particle } \\
\text { Diameter } \\
(\mu \mathrm{m})\end{array}$} & \multicolumn{2}{|c|}{ Mass Distribution } & \multicolumn{2}{|c|}{ Particle Distribution } \\
\hline & $\begin{array}{c}\text { corresponding } \\
\text { mass } \\
\text { fraction }\end{array}$ & $\begin{array}{l}\text { cumulative } \\
\text { mass } \\
\text { fraction }\end{array}$ & $\begin{array}{l}\text { corresponding } \\
\text { particle } \\
\text { fraction }\end{array}$ & $\begin{array}{l}\text { cumulat } \\
\text { partic } \\
\text { fracti }\end{array}$ \\
\hline $\begin{array}{l}0.25 \\
0.35 \\
0.50 \\
1.5 \\
3.0 \\
5.0 \\
8.0 \\
15 \\
30 \\
52 \\
77 \\
150 \\
300 \\
600 \\
1000 \\
1700 \\
2500 \\
3000\end{array}$ & $\begin{array}{l}3.8 \times 10^{-9} \\
9.1 \times 10^{-9} \\
6.7 \times 10^{-8} \\
4.2 \times 10^{-7} \\
4.5 \times 10^{-5} \\
6.4 \times 10^{-5} \\
4.2 \times 10^{-4} \\
1.9 \times 10^{-3} \\
1.7 \times 10^{-2} \\
8.4 \times 10^{-3} \\
1.1 \times 10^{-2} \\
9.2 \times 10^{-2} \\
0.155 \\
0.263 \\
0.223 \\
0.217 \\
4.9 \times 10^{-3} \\
6.8 \times 10^{-3}\end{array}$ & $\begin{array}{l}3.8 \times 10^{-9} \\
1.3 \times 10^{-8} \\
8.0 \times 10^{-8} \\
5.0 \times 10^{-7} \\
4.6 \times 10^{-5} \\
1.1 \times 10^{-4} \\
5.3 \times 10^{-4} \\
2.4 \times 10^{-3} \\
1.9 \times 10^{-2} \\
2.7 \times 10^{-2} \\
3.9 \times 10^{-2} \\
0.13 \\
0.29 \\
0.55 \\
0.77 \\
0.99 \\
0.99+ \\
\sim 1.00\end{array}$ & $\begin{array}{l}0.124 \\
0.110 \\
0.069 \\
0.110 \\
0.204 \\
0.063 \\
0.102 \\
0.124 \\
0.080 \\
7.3 \times 10^{-3} \\
3.8 \times 10^{-3} \\
3.2 \times 10^{-3} \\
7.1 \times 10^{-4} \\
1.5 \times 10^{-4} \\
2.8 \times 10^{-5} \\
5.5 \times 10^{-6} \\
3.8 \times 10^{-8} \\
2.3 \times 10^{-8}\end{array}$ & $\begin{array}{r}0.12 \\
0.23 \\
0.30 \\
0.41 \\
0.62 \\
0.68 \\
0.78 \\
0.91 \\
0.99 \\
>0.99\end{array}$ \\
\hline
\end{tabular}

a. Particle diameters are geometric, not aerodynamic.

b. Particle distribution based on spherical particles of stated diameters and $11.45 \mathrm{~g} / \mathrm{cm}^{3}$ for the $\mathrm{PuO}_{2}$ density. 
Table IV.

Size Distribution for $\mathrm{PuO}_{2}$ Prepared by High

Temperature oxidation of $\mathrm{PuH}_{2}$ in Air. Values derived from data by stakebake and Robinson. 18

\begin{tabular}{lllll}
$\begin{array}{l}\text { Particle } \\
\text { Diameter } \\
(\mu \mathrm{m})\end{array}$ & $\begin{array}{c}\text { Mass Distribution } \\
\text { corresponding } \\
\text { mass } \\
\text { fraction }\end{array}$ & $\begin{array}{c}\text { cumulative } \\
\text { mass } \\
\text { fraction }\end{array}$ & $\begin{array}{c}\text { Particle } \\
\text { corresponding } \\
\text { particle } \\
\text { fraction }\end{array}$ & $\begin{array}{c}\text { cumulative } \\
\text { particle } \\
\text { fraction }\end{array}$ \\
\hline & & & & \\
0.25 & $2.4 \times 10^{-7}$ & $2.4 \times 10^{-7}$ & 0.02 & 0.02 \\
0.35 & $9.4 \times 10^{-7}$ & $1.2 \times 10^{-6}$ & 0.03 & 0.05 \\
0.50 & $1.6 \times 10^{-5}$ & $1.7 \times 10^{-5}$ & 0.04 & 0.09 \\
1.5 & $5.8 \times 10^{-4}$ & $6.0 \times 10^{-4}$ & 0.41 & 0.50 \\
3.0 & 0.018 & 0.02 & 0.22 & 0.72 \\
5.0 & 0.063 & 0.08 & 0.16 & 0.88 \\
8.0 & 0.110 & 0.19 & 0.07 & 0.95 \\
15 & 0.220 & 0.41 & 0.037 & 0.994 \\
20 & 0.178 & 0.59 & 0.007 & 0.997 \\
25 & 0.147 & 0.74 & 0.003 & 0.998 \\
30 & 0.084 & 0.82 & 0.001 & 0.999 \\
35 & 0.131 & 0.95 & 0.001 & 0.9999 \\
45 & 0.036 & 0.99 & 0.0001 &
\end{tabular}

a. Particle diameters are geometric, not aerodynamic.

b. Mass distribution calculated for spherical oxide particles $11.45 \mathrm{~g} / \mathrm{cm}^{3}$ for the $\mathrm{PuO}_{2}$ density. 
Table V. Size Distribution obtained for $\mathrm{PuO}_{2}$ Using a Fracture Model to Calculate the Particle Redistribution During $\mathrm{PuH}_{2}$ oxidation.

Particle Diameter ${ }^{a}$ $(\mu \mathrm{m})$ 0.5

1.5

3.0

5.0

8.0

15

20

25

30

35

\section{Mass Distribution} corresponding cumulative mass fraction mass fraction

$$
\begin{aligned}
& 7.2 \times 10^{-6} \\
& 2.4 \times 10^{-4} \\
& 2.3 \times 10^{-3} \\
& 1.1 \times 10^{-2} \\
& 7.2 \times 10^{-2} \\
& 0.130
\end{aligned}
$$

0.139

0.335

0.288

$2.2 \times 1.0^{-2}$

$7.2 \times 10^{-6}$
$2.5 \times 10^{-4}$
$2.5 \times 10^{-3}$
$1.5 \times 10^{-2}$
$8.7 \times 10^{-2}$
0.22
0.36
0.69
0.98
1.00

Particle Distribution corresponding cumulative particle fraction particle fraction

$\begin{array}{lr}0.075 & 0.08 \\ 0.383 & 0.46 \\ 0.112 & 0.57 \\ 0.122 & 0.68 \\ 0.187 & 0.87 \\ 0.051 & 0.92 \\ 0.027 & 0.95 \\ 0.028 & 0.98 \\ 0.014 & 0.99 \\ 6.6 \times 10^{-4} & -1.00\end{array}$

a. Particle diameters are geometric, not aerodynamic.

b. Particle distribution calçulated for spherical oxide particles with $11.45 \mathrm{~g} / \mathrm{cm}^{3}$ for the $\mathrm{PuO}_{2}$ density. 


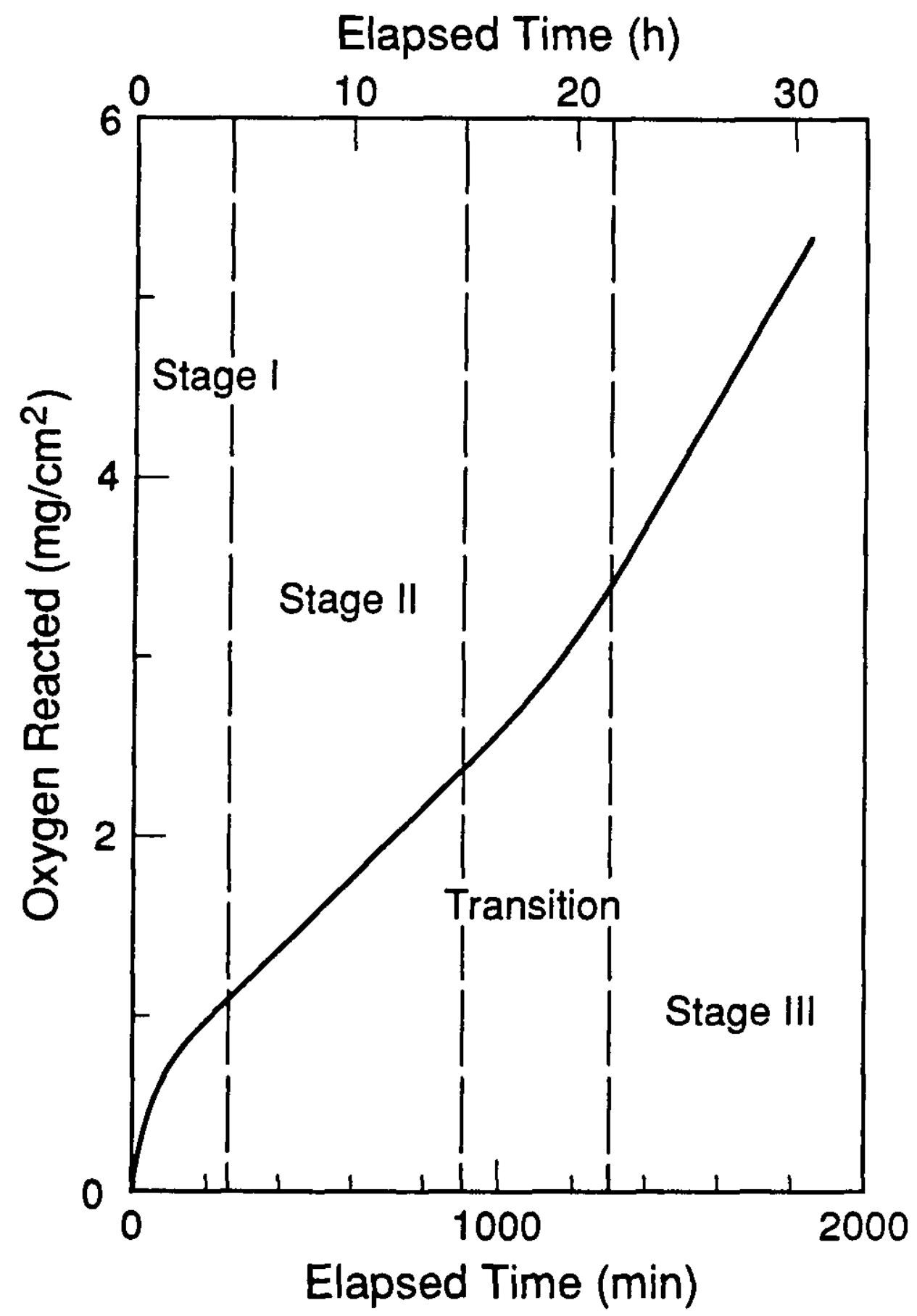

Figure 1. The stages of reaction observed for oxidation of plutonium metal. The curve is based on data fof the $\mathrm{Pu}+\mathrm{O}_{2}$ reaction at $300^{\circ} \mathrm{C}$ and 1 torr $\mathrm{O}_{2}$ pressure. 10 


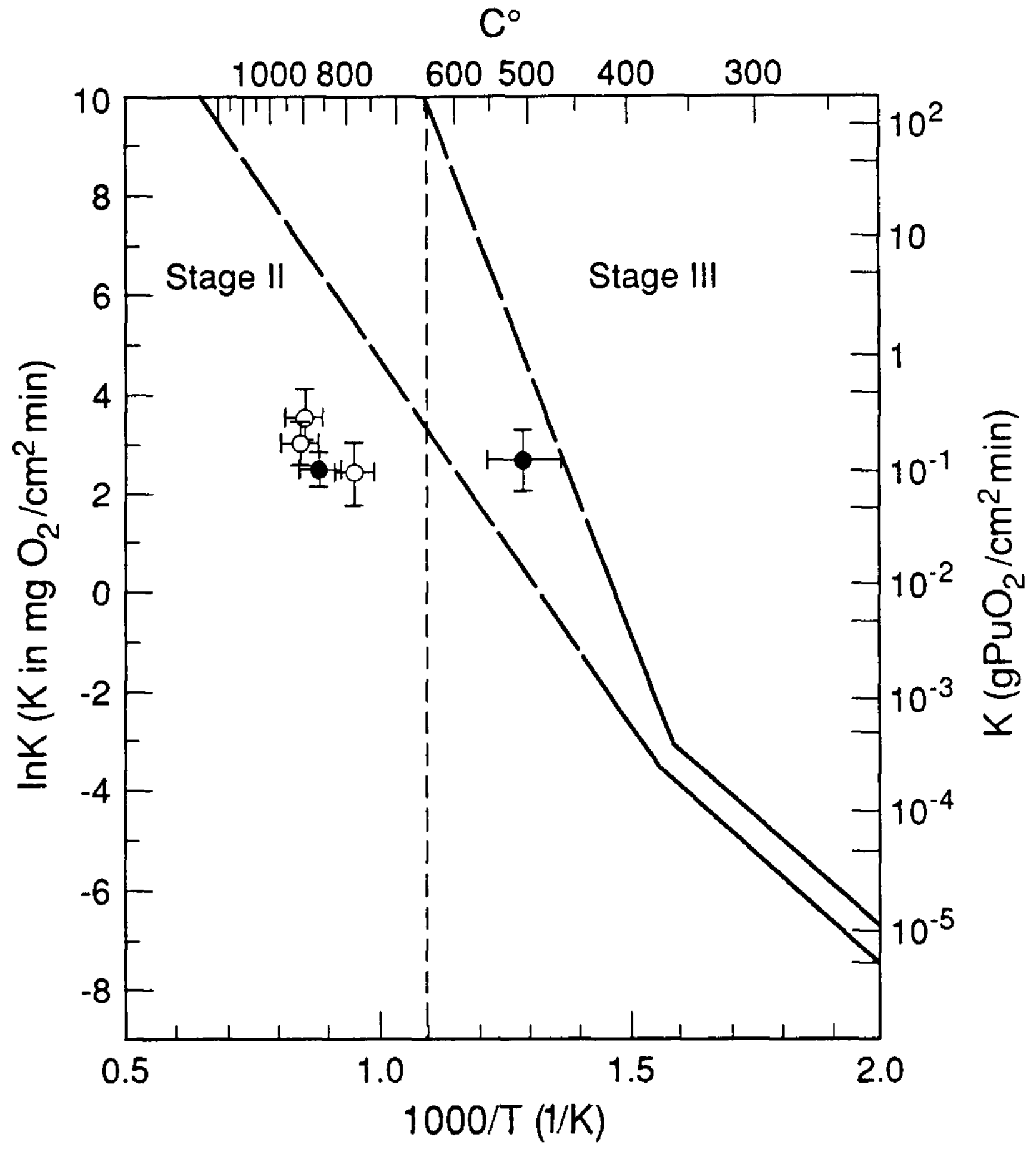

Figure 2. The temperature dependence of the oxidation rate for $\mathrm{Pu}_{\mathrm{O}} \mathrm{O}_{2}$. Arrhenius curves are from kinetic measurements by stakebake ${ }^{10}$; rates shown by solid, and open symbols are derived from data of stewart ${ }^{1}$ and Mishima, 3 respectively. 


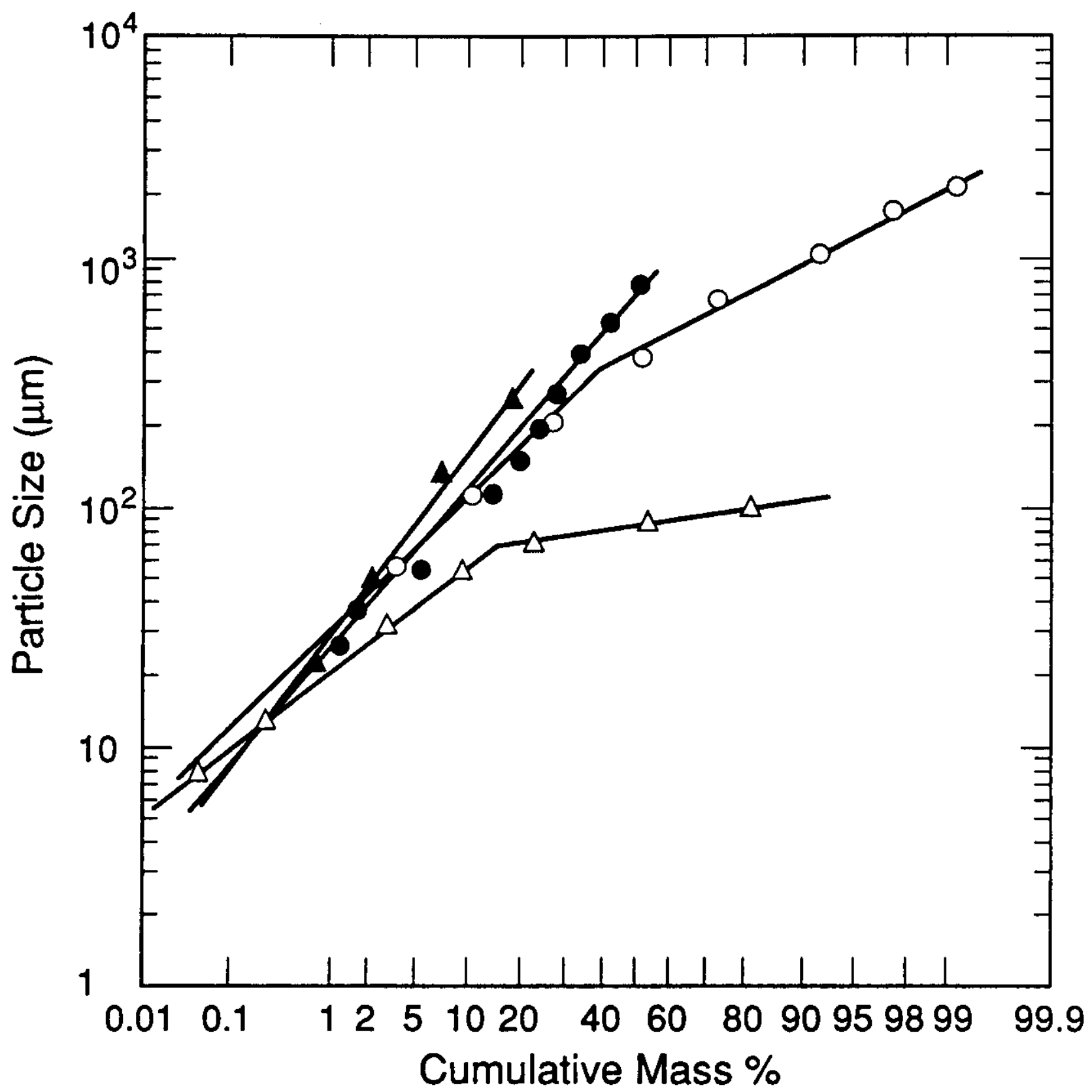

Figure 3. Cumulative mass distribution for large product particles of Pu+gas reactions. Data for hightemperature $\mathrm{PuO}_{2}$ are shown by circles and solid triangles ${ }^{2}$ data for $\mathrm{PuH}_{2}$ are shown by open 


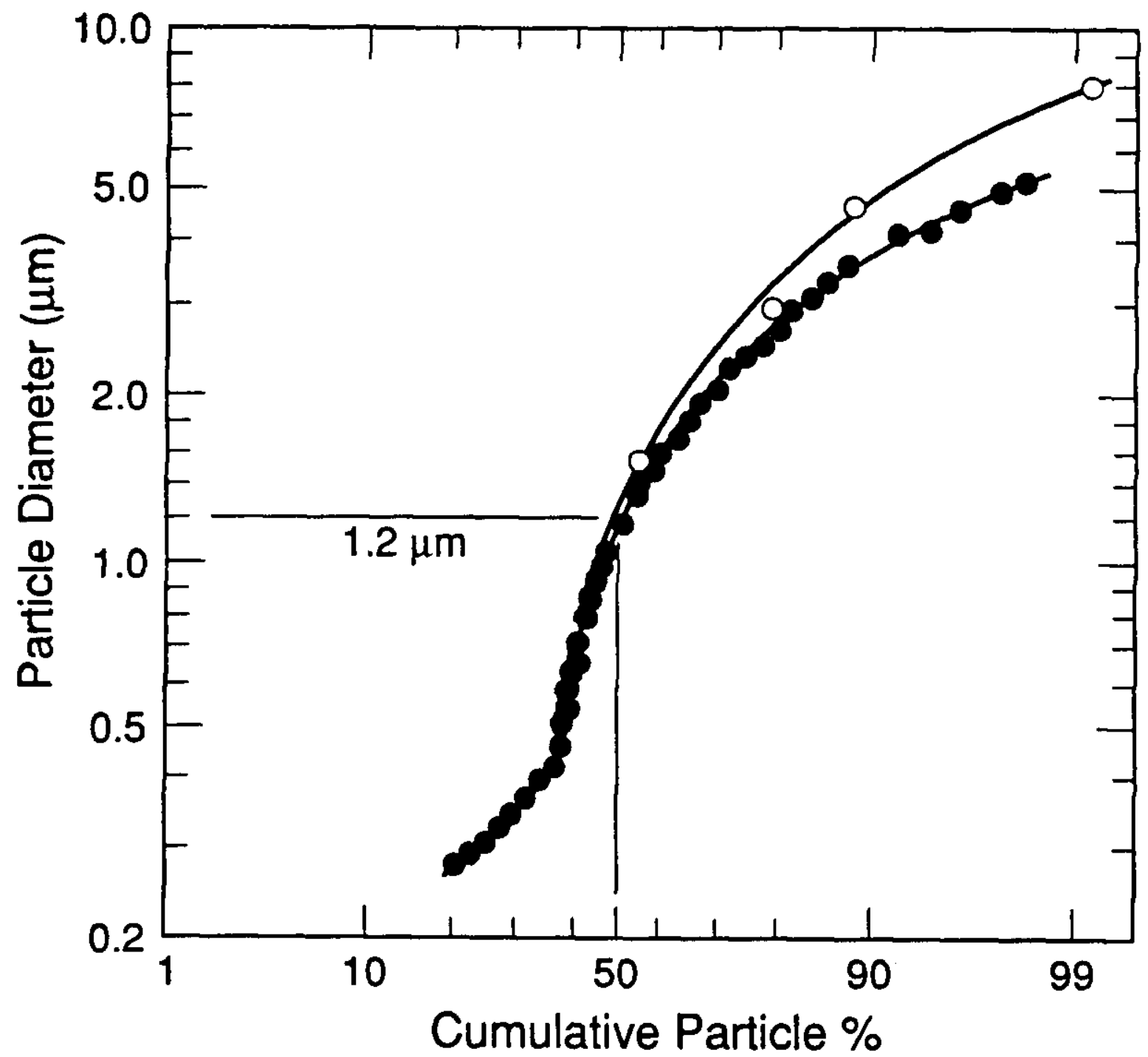

Figure 4. Cumulative particle distributions for small product particles of pu+gas reactions. Data for entrained PuO $_{2}$ are shown by solid circles ${ }^{3}$; data for $\mathrm{PuH}_{2}$
particles $<10 \mathrm{~mm}$ are shown by open circles. 


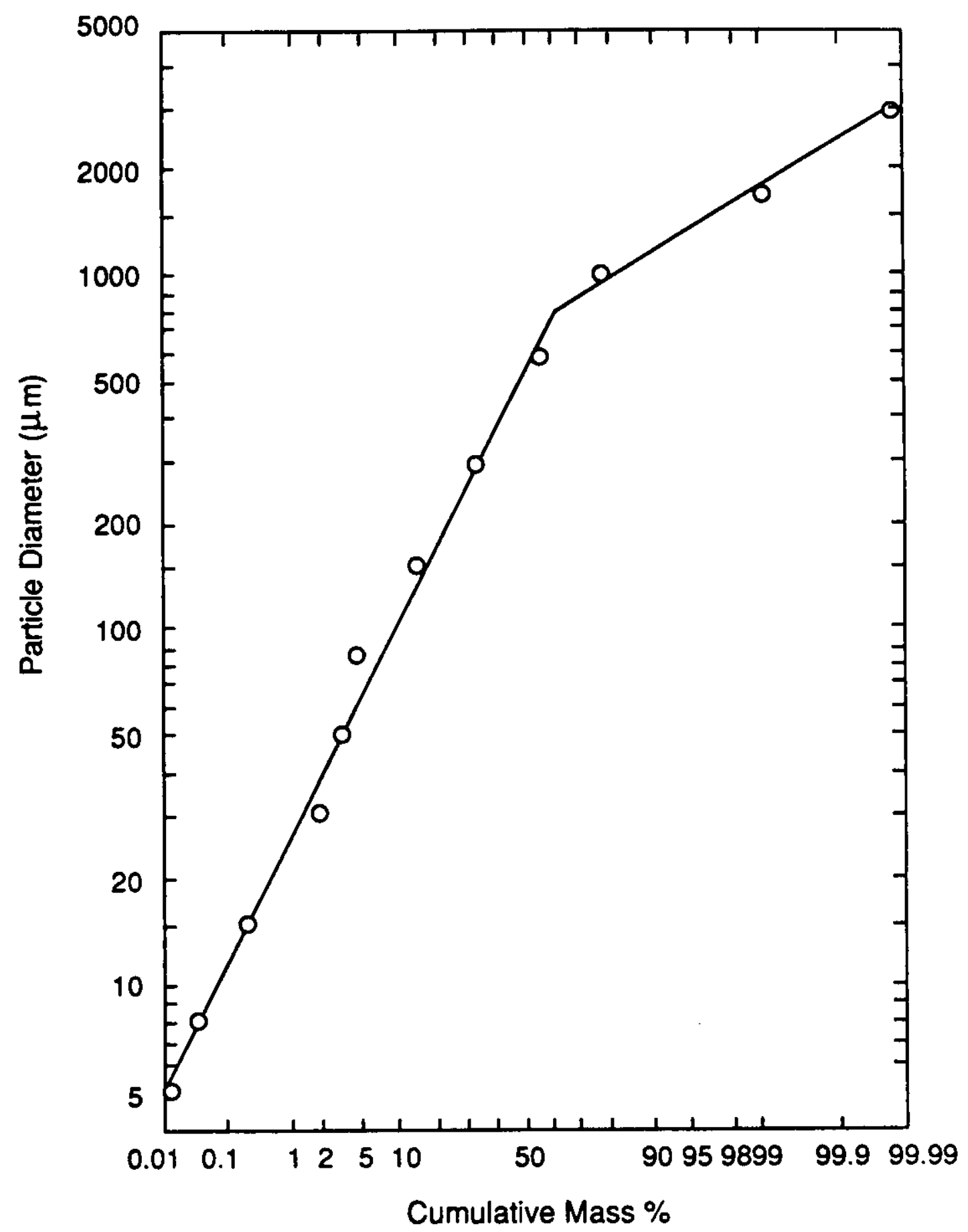

Figure 5. The cumulative mass distribution derived for oxide formed by the $\mathrm{Pu}+\mathrm{O}_{2}$ reaction at temperatures above $500^{\circ} \mathrm{C}$. 


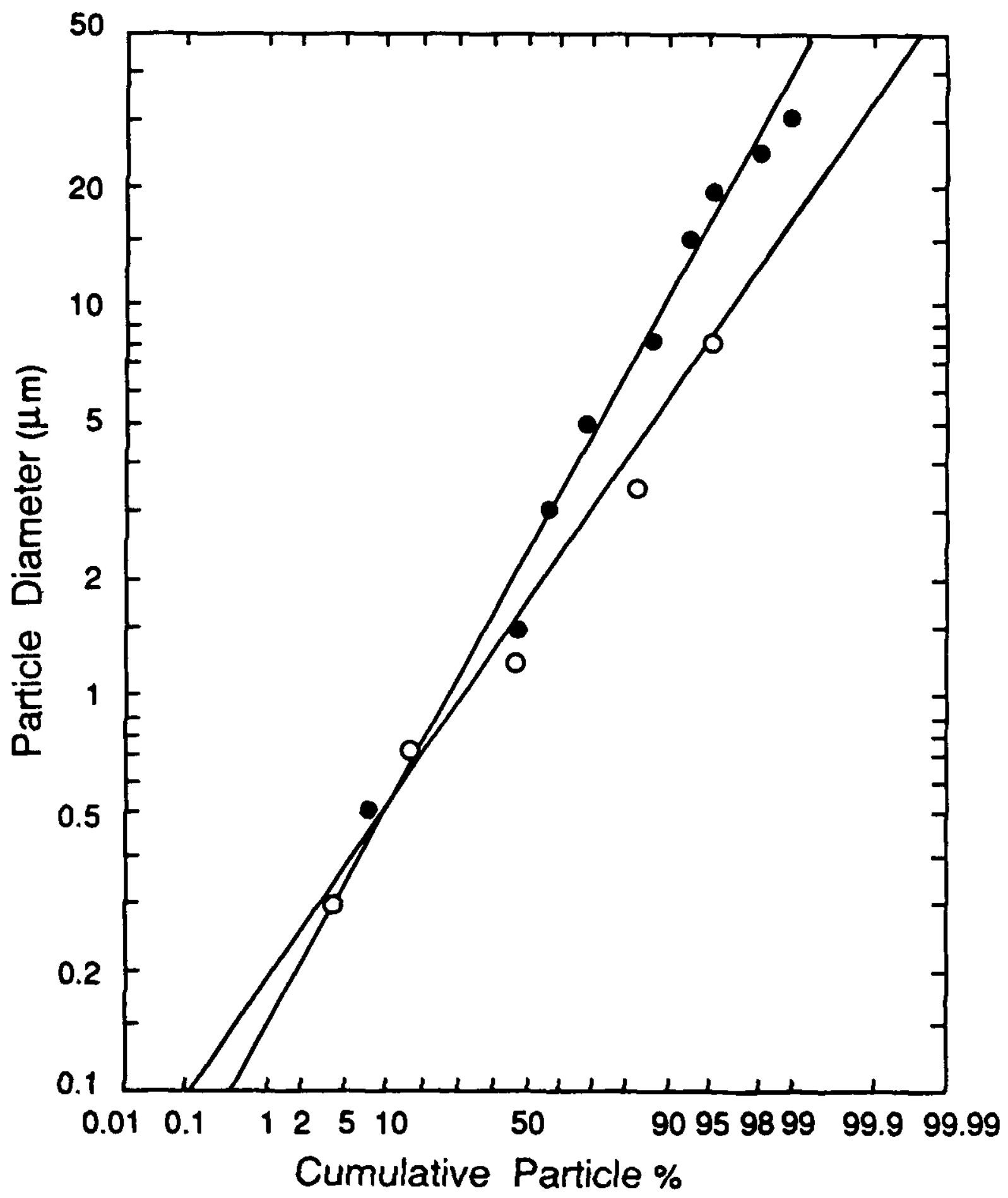

Figure 6. Comparison of cumulative particle distributions for oxide formed by the $\mathrm{PuH}_{2}+\mathrm{O}_{2}$ reaction. Experimental data from Stakebake and Robinson 18 are shown by open symbols; values predicted using the fracture model are shown by solid symbols. 


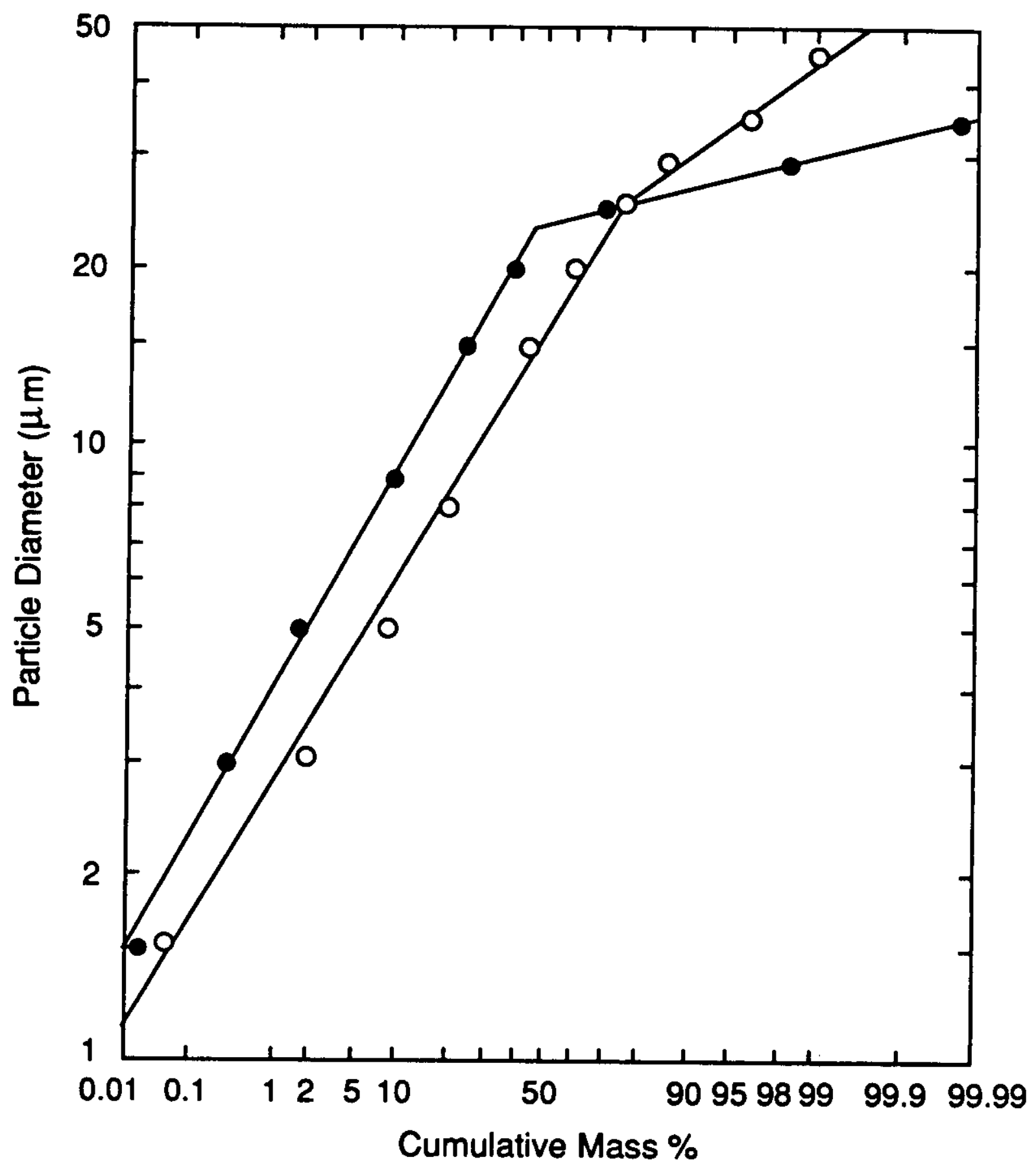

Figure 7. Comparison of cumulative mass distributions for oxide formed by the $\mathrm{PuH}_{2}+\mathrm{O}_{2}$ reaction. Experimental data from Stakebake and Robinson 18 are shown by open symbols; values predicted using the fracture model are shown by solid symbols. 


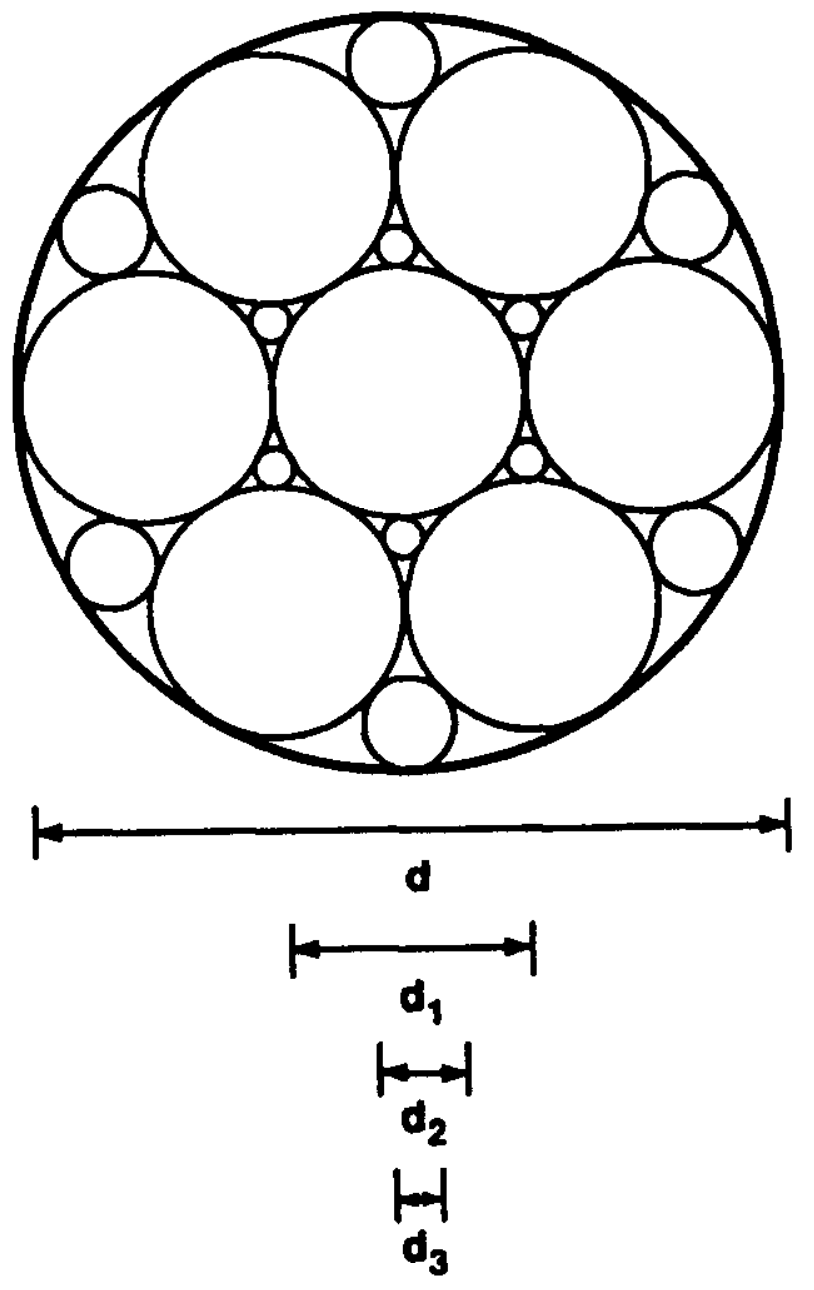

Figure 8. Closest-packed planar array of spherical product particles with diameters $d_{1}, d_{2}$ and $d_{3}$ formed by fracture of a spherical reactant particle with diameter d. 


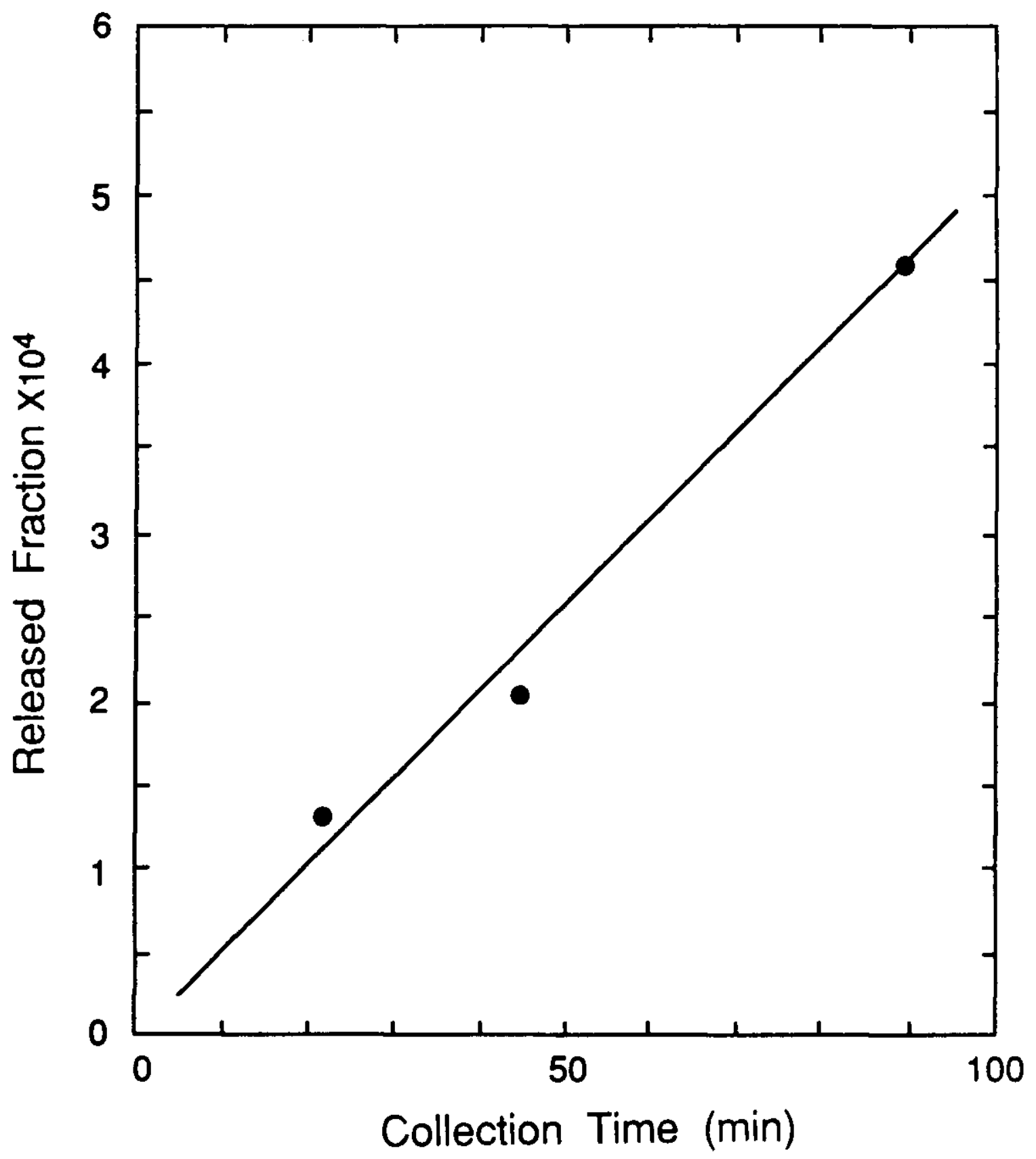

Figure 9. Dependence of the released fraction of $\mathrm{PuO}_{2}$ particles on the collection time. 
This report has been reproduced directly from the best available copy.

It is available to DOE and DOE contractors from the Office of Scientific and Technical Information,

P.O. Box 62,

Oak Ridge, TN 37831.

Prices are available from

(615) 576-8401, FTS 626-8401.

It is available to the public from the National Technical Information Service,

U.S. Department of Commerce,

5285 Port Royal Rd.,

Springfield, VA 22161. 


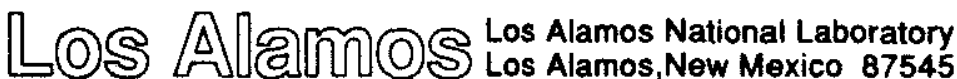

